\title{
Effect of Sodium Glucose Cotransporter 2 Inhibitors With Low SGLT2/SGLT1 Selectivity on Circulating Glucagon-Like Peptide 1 Levels in Type 2 Diabetes Mellitus
}

\author{
Kohzo Takebayashi ${ }^{\mathrm{a}, \mathrm{b}}$, Toshihiko Inukai ${ }^{\mathrm{a}}$
}

\begin{abstract}
Sodium glucose cotransporter 2 (SGLT2) inhibitors are a new class of antidiabetic drugs that improve glycemic control by inhibiting reabsorption of glucose filtered through the renal glomerulus. Use of drugs in this class has increased because of their effect of decreasing body weight and a low risk for hypoglycemia, in addition to a relatively strong glucose-lowering effect. SGLT2 inhibitors such as canagliflozin and sotagliflozin (a SGLT1/SGLT2 dual inhibitor) also have a mild or moderate intestinal and renal SGLT1 inhibitory effect because of their relatively weak selectivity for SGLT2 over SGLT1. Recent evidence shows that these SGLT2 inhibitors with low SGLT2/ SGLT1 selectivity elevate the level of circulating glucagon like peptide-1 (GLP-1), an incretin hormone that promotes insulin secretion in pancreatic $\beta$ cells. This effect probably occurs partly via inhibition of intestinal SGLT1, and the elevation of active GLP-1 levels is especially apparent when these drugs are co-administered with dipeptidyl peptidase 4 (DPP4) inhibitors. These findings suggest that a combination of canagliflozin or sotagliflozin and a DPP4 inhibitor can provide a beneficial effect associated with elevation of circulating active GLP-1 and may serve as a treatment for patients with type 2 diabetes.
\end{abstract}

Keywords: Canagliflozin; Sotagliflozin; SGLT1; Type 2 diabetes

\section{Introduction}

Sodium glucose cotransporter 2 (SGLT2) inhibitors are a new class of antidiabetic drugs that improve glycemic control by inhibiting reabsorption of glucose filtered through the renal glomerulus $[1,2]$. Use of drugs in this class has increased worldwide because of the definitive effect of a decrease of body weight and a low risk for hypoglycemia, in addition to a

\section{Manuscript submitted June 19, 2017, accepted July 1, 2017}

aDepartment of Internal Medicine, Dokkyo Medical University Koshigaya Hospital, Koshigaya, Saitama, Japan

${ }^{b}$ Corresponding Author: Kohzo Takebayashi, Department of Internal Medicine, Dokkyo Medical University Koshigaya Hospital, 2-1-50, Minami-Koshigaya, Koshigaya, Saitama 343-8555, Japan. Email: takeb@gmail.plala.or.jp

doi: https://doi.org/10.14740/jocmr3112w relatively strong glucose-lowering effect independent of insulin action $[1,2]$. Notably, a recent prospective study (the EMPGREG OUTCOME study) showed that empagliflozin (a SGLT2 inhibitor) reduced cardiovascular outcomes and death from any cause in patients with type 2 diabetes at high risk for cardiovascular events [3]. In contrast, a beneficial effect on cardiovascular events could not be proved using dipeptidyl peptidase 4 (DPP4) inhibitors [4-6], another widely used class of antidiabetic agents. DPP4 inhibitors mainly improve glycemic control by increasing circulating active glucagon-like peptide 1 (GLP$1)$, an incretin hormone that promotes insulin secretion in pancreatic $\beta$ cells, by blocking degradation of GLP-1 by DPP4 [7].

SGLT2 is expressed in the S1 segment of the proximal tubules in the kidney, and inhibition of this molecule results in a marked increase in urinary glucose excretion (UGE) [810]. SGLT2 is a high-capacity and low-affinity glucose transporter that is responsible for approximately $90 \%$ of glucose absorption in kidney [9]. Interestingly, glucose reabsorption in renal tubules mediated by SGLT2 is promoted in patients with type 2 diabetes, compared with non-diabetic subjects [11,12]. SGLT1 is expressed in the S3 segment of the proximal renal tubules, which is located more distally from the glomerulus compared with the location of S1. SGLT1 is a low-capacity and high-affinity transporter that accounts for absorption of the remaining $10 \%$ of the glucose [8]. The effect of SGLT1 on glucose absorption can be enhanced in the presence of an SGLT2 inhibitor due to a compensatory mechanism $[8,13-$ 15]. Therefore, SGLT1 transport of glucose may weaken the glucose-lowering effect of SGLT2 inhibitors [8, 13-15].

SGLT1 is also abundantly expressed in the brush-border membrane surface of villi lining the lumen of the upper small intestine, where it contributes to absorption of glucose or galactose from the gastrointestinal tract $[16,17]$. Glucose absorption in the small intestine via SGLT1 in patients with type 2 diabetes generally increases relative to that in non-diabetic subjects [18]. A genetic deficiency of SGLT1 can cause glucose-galactose malabsorption in newborn infants that results in life-threatening dehydration due to severe diarrhea if they do not receive sugar free diet [19]. However, it is likely that mild to moderate pharmacological inhibition of SGLT1 in the small intestine reduces postprandial excursion of glucose without causing severe diarrhea or malabsorption [20]. In this respect, an SGLT2 inhibitor with a mild or moderate inhibitory effect on SGLT1 may improve glycemic control more effectively than highly selective SGLT2 inhibitors in patients with type 2 diabetes by increased 
UGE via dual blocking of SGLT2 and SGLT1 in renal tubules and by inhibition of postprandial glucose absorption via blocking of SGLT1 in endothelial cells in the small intestine.

Canagliflozin is an SGLT2 inhibitor that is used clinically worldwide $[1,12]$. Canagliflozin has relatively weak selectivity for SGLT2 over SGLT1, compared with other SGLT2 inhibitors such as dapagliflozin, empagliflozin, and tofogliflozin, which are highly selective SGLT2/SGLT1 inhibitors [21, 22]; that is, canagliflozin has a mild inhibitory effect on SGLT1, in addition to relatively strong inhibition of SGLT2. Sotagliflozin (also known as LX4211) is a dual SGLT1/SGLT2 inhibitor that is under development for clinical use and has a stronger inhibitory effect on SGLT1 compared with current SGLT2 inhibitors, including canagliflozin $[20,23]$. Interestingly, both canagliflozin and sotagliflozin increase circulating GLP-1 levels [20, 23 31 , which is enhanced when these drugs are co-administered with DPP4 inhibitors [24, 25, 28]. The detailed mechanisms are not fully apparent, but the effect may be partially mediated by passage of glucose from the upper to lower intestine based on SGLT1 inhibition in endothelial cells in the upper small intestine [23-28]. However, empagliflozin, a highly selective SGLT2 inhibitor, has also recently been shown to increase circulating GLP-1 [32], although the effect was relatively mild. This suggests that the mechanisms underlying circulating GLP-1 elevation by canagliflozin or sotagliflozin are complex and that multiple mechanisms, including those independent of SGLT1 inhibition, may be involved. It is unclear whether the robust elevating effect of SGLT2 inhibitors on circulating GLP-1 levels is specific for non- (or weak) selective SGLT2 inhibitors such as canagliflozin and sotagliflozin, but this effect may provide additional benefits in treatment of type 2 diabetes, especially in co-treatment with DPP4 inhibitors. In this paper, we discuss the possible mechanisms of elevation of circulating GLP-1 by SGLT2 inhibitors, with a particular focus on canagliflozin and sotagliflozin, which also have an inhibitory effect on SGLT1.

\section{Elevation of Circulating GLP-1 by Canagliflozin and Sotagliflozin}

\section{Canagliflozin}

Canagliflozin was developed in Japan and was approved by the US Food and Drug Administration (FDA) in March 2013, as the first clinically available SGLT2 inhibitor in the USA. Canagliflozin was approved in Europe in November 2013 and in Japan in October 2014. In the USA and Europe, the recommended starting dose is $100 \mathrm{mg}$ once a day before the first meal. This can be increased to $300 \mathrm{mg}$ a day depending on the degree of glycemic control if the patient tolerates $100 \mathrm{mg}$ and has an estimated glomerular filtration rate (eGFR) $\geq 60 \mathrm{~mL} /$ $\mathrm{min} / 1.73 \mathrm{~m}^{2}$ [33-36]. However, only use of a dose of $100 \mathrm{mg}$ once a day is currently approved in Japan.

\section{Pharmacokinetics and pharmacodynamics}

Orally administered canagliflozin is rapidly absorbed in the gastrointestinal tract in a dose-dependent manner at $50-300$ $\mathrm{mg}$ /day and its oral bioavailability is approximately $65 \%$, with a maximum effect 30 - 120 min after administration $[33,36]$. Accumulation of canagliflozin in plasma increases to $36 \%$ following multiple doses ranging from 100 to $300 \mathrm{mg} /$ day [33, 36]. The half-life $\left(t_{1 / 2}\right)$ is $11-13 \mathrm{~h}$ and this relatively long $t_{1 / 2}$ permits a once-a-day regimen [37]. Plasma protein binding is very high $(99 \%)$ and is independent of the plasma concentration of canagliflozin and of liver and renal damage [33, 36]. Canagliflozin is metabolized into two inactive O-glucuronide metabolites, named M5 and M7. In healthy subjects, canagliflozin is excreted in feces as $41.5 \%$ unchanged, $7 \%$ hydroxylated, and 3.2\% O-glucuronidated forms, and in urine as $<1 \%$ unchanged form, 7-10\% M5 and 21-32\% M7 [33, 36].

The half-maximal inhibitory concentrations (IC50) of canagliflozin in humans are $663 \pm 180 \mathrm{nM}$ for SGLT1 and 4.2 $\pm 1.5 \mathrm{nM}$ for SGLT2, giving an SGLT2 selectivity of 150 - to 160 -fold $[21,38]$. The threshold for glucose excretion (RTG) in kidney is reduced from 240 to $70-90 \mathrm{mg} / \mathrm{dL}$ at a dose of 300 $\mathrm{mg}$ of canagliflozin, and this results in UGE of approximate 77 - $119 \mathrm{~g} /$ day, which is comparable to a calorie loss of $308-476$ $\mathrm{kcal} /$ day [33]. This increase of 24-h UGE by canagliflozin is about $25 \%$ higher than that with dapagliflozin at its clinically approved maximal dose of $10 \mathrm{mg}$ [39]. The maximum plasma concentration of canagliflozin is not altered by renal dysfunction $[33,36]$. Canagliflozin $(300 \mathrm{mg})$ given before a meal inhibits postprandial glucose excursion in patients with type 2 diabetes [26]. It contrast, dapagliflozin in healthy subjects [39] and empagliflozin in patients with type 2 diabetes [32] have no effect on postprandial excursion of glucose. This postprandial effect of canagliflozin seems to be explained by its relatively strong inhibition of SGLT1, compared with dapagliflozin and empagliflozin. Importantly, blood levels of canagliflozin are not sufficient to inhibit systemic SGLT1, but the maximum level in the lumen in the gastrointestinal tract is high enough to inhibit SGLT1 in the brush-border membrane lining of the lumen of the small intestine $[25,38]$.

\section{Clinical efficacy of canagliflozin for glycemic control}

Changes of HbAlc from baseline after canagliflozin monotherapy for 26 weeks were $-0.77 \%$ at $100 \mathrm{mg}$ /day (baseline HbA1c: $8.1 \%$ ) and $-1.03 \%$ at $300 \mathrm{mg} /$ day (baseline HbA1c: $8.0 \%$ ) [40], each with a significant difference vs. placebo $(+0.14 \%$; baseline HbA1c: $8.0 \%)$. In a comparison of the effects of canagliflozin and glimepiride (a sulfonylurea) for 52 weeks in patients with type 2 diabetes treated with metformin, the changes in HbA1c were $-0.82 \%$ with canagliflozin $100 \mathrm{mg} /$ day, $-0.93 \%$ with canagliflozin $300 \mathrm{mg} /$ day, and $-0.81 \%$ with titrated glimepiride, with significant superiority of canagliflozin $300 \mathrm{mg}$ /day vs. glimepiride [41]. In a similar comparison of canagliflozin and sitagliptin (a DPP4 inhibitor) for 52 weeks in patients with type 2 diabetes treated with metformin, the changes in HbA1c were $-0.73 \%$ with canagliflozin $100 \mathrm{mg} /$ day, $-0.88 \%$ with canagliflozin $300 \mathrm{mg} /$ day, and $-0.73 \%$ with sitagliptin $100 \mathrm{mg} /$ day. Again, there was significant superiority of canagliflozin $300 \mathrm{mg}$ /day vs. sitagliptin $100 \mathrm{mg} /$ day [42]. A recent systematic review and network meta-analysis showed 
changes of $\mathrm{HbA} 1 \mathrm{c}$ with canaglifflozin of $-0.86 \%$ at $300 \mathrm{mg} /$ day and $-0.76 \%$ at $100 \mathrm{mg} /$ day, while those with the clinically approved maximum doses of dapagliflozin $(10 \mathrm{mg}$ /day $)$ and empagliflozin $(25 \mathrm{mg} /$ day $)$ were both $-0.66 \%$, suggesting a relatively strong glucose-lowering effect of canagliflozin [43].

\section{Effect of canagliflozin on circulating GLP-1: animal studies}

Oguma et al investigated the effects of canagliflozin, teneligliptin (a DPP4 inhibitor) and their combination therapy on plasma glucose, insulin, and active GLP-1 (aGLP-1) levels in Zucker diabetic fatty (ZDF) rats, a genetic animal model of obese type 2 diabetes [24]. After oral administration of glucose solution, plasma glucose significantly increased in vehicle-treated ZDF rats, and canagliflozin and teneligliptin monotherapy both significantly suppressed plasma glucose compared with that in vehicle-treated ZDF rats. As expected, combination therapy of these drugs further decreased plasma glucose. Plasma insulin levels after glucose administration were increased by teneligliptin, but not influenced by canagliflozin. A mild, transient and non-significant increase of plasma aGLP-1 occurred with canagliflozin $(10 \mathrm{mg} / \mathrm{kg})$ after glucose administration. Canagliflozin also increased the area under the curve $\left(\mathrm{AUC}_{0-2 \mathrm{~h}}\right)$ of aGLP-1 by about three- and fourfold at doses of 3 and $10 \mathrm{mg} /$ $\mathrm{kg}$, respectively, compared with vehicle, but these increases were not significant. Teneligliptin $(0.3 \mathrm{mg} / \mathrm{kg})$ resulted in an approximately eightfold greater $\mathrm{AUC}_{0-2 \mathrm{~h}}$ of aGLP compared with vehicle, and again the change was not significant. However, a significant increase in AUC of about 47 -fold (compared to vehicle) occurred with co-administration of canagliflozin (10 $\mathrm{mg} / \mathrm{kg})$ and teneligliptin $(0.3 \mathrm{mg} / \mathrm{kg})$. In this study, teneligliptin inhibited plasma DPP4 activity by about $75 \%$ and this was not influenced by addition of canagliflozin [24].

The same authors investigated the effect of intestinal SGLT1 inhibition on plasma aGLP-1 levels in normal and diabetic rodents [25]. In male C57BL6J mice (non-diabetic control mice), canagliflozin $(10 \mathrm{mg} / \mathrm{kg}$ ) significantly increased plasma aGLP-1 at 15 and $30 \mathrm{~min}$ in an oral glucose tolerance test (OGTT) compared with vehicle, and a marked elevation was noted in combination with sitagliptin $(10 \mathrm{mg} / \mathrm{kg})$. In SD rats (an animal model of type 2 diabetes), canagliflozin in combination with sitagliptin $(10 \mathrm{mg} / \mathrm{kg})$ dose-dependently increased $\mathrm{AUC}_{0-2 \mathrm{~h}}$ of aGLP-1 during the OGTT. Canagliflozin + sitagliptin $(10 \mathrm{mg} / \mathrm{kg})$ also significantly increased the $\mathrm{AUC}_{0}$. $3 \mathrm{~h}$ of aGLP-1, but the effect was weaker than that of sitagliptin + 3-(4-cyclopropylphenylmethyl)-1-(beta-D-glucopyranosyl)4-methylindole (CGMI), which is a more potent inhibitor of SGLT1 than canagliflozin; the IC50 values of CGMI for human SGLT1 and SGLT2 are 22.1 and $1.39 \mathrm{nM}$, respectively, with a 15.9-fold selectivity for SGLT2 over SGLT1. Taken together, these findings suggest that both the dose and SGLT1 selectivity are important for increased GLP-1 secretion and that the effect is enhanced by a combination with a DPP4 inhibitor. This study also showed that the potentially inhibitory effect of canagliflozin on carbohydrate absorption in the gastrointestinal tract is transient after sucrose loading. Canagliflozin increased carbohydrate content in the upper and middle intestine (but not in the lower intestine) at $1 \mathrm{~h}$, but the effect vanished at $6 \mathrm{~h}$ [25].

\section{Effect of canagliflozin on circulating GLP-1: clinical studies}

Polidori et al investigated the effects of canagliflozin on intestinal glucose absorption in 20 healthy subjects using a dual tracer method in a study with a two-period, crossover design [26]. Canagliflozin decreased postprandial glucose and insulin, increased 0- to 6-h UGE, and delayed the rate of appearance of oral glucose $(\mathrm{RaO})$ in plasma, as evaluated using oral $14 \mathrm{C}$-glucose. Canagliflozin significantly decreased $\mathrm{AUC}_{0}-1 \mathrm{~h}$ of $\mathrm{RaO}$ by $31 \%$ and $\mathrm{AUC}_{0-2 \mathrm{~h}}$ by $20 \%$. In contrast, canagliflozin treatment over 2 - $6 \mathrm{~h}$ increased $\mathrm{RaO}$, such that $\mathrm{AUC}_{0-6 \mathrm{~h}}$ of $\mathrm{RaO}$ was only $6 \%$ lower compared with placebo. It was concluded that canagliflozin can reduce postprandial plasma glucose and insulin levels by increasing UGE mediated by SGLT2 inhibition in kidney and by delaying glucose absorption in the intestine, probably due to inhibition of SGLT1. Consistent with delayed glucose absorption, there were changes in the levels of GLP-1 and other gut peptides, including glucose-dependent insulinotropic peptide (GIP), another incretin hormone that promotes insulin secretion in pancreatic $\beta$ cells, and peptide YY (PYY), an anorectic hormone secreted from $\mathrm{L}$ cells that reduces food intake directly or via a vagal afferent pathway $[44,45] . \mathrm{AUC}_{0-2 \mathrm{~h}}$ for total GLP-1 (tGLP-1) was significantly increased by $35 \%$ with canagliflozin compared with placebo. The increase of tGLP-1 was large from $30 \mathrm{~min}$ to $2 \mathrm{~h}$, but not from 0 to 30 min. A similar tendency was found for $\mathrm{AUC}_{0-2 \mathrm{~h}}$ of aGLP-1, but the increase was not significant. Canagliflozin decreased incremental postprandial GIP by $50 \%$ and increased incremental postprandial PYY by $60 \%$ compared with placebo.

We recently investigated the effect of canagliflozin on GLP-1 levels in patients with type 2 diabetes [46]. Canagliflozin (100 mg a day) $(n=15)$ for 3 days significantly increased $\mathrm{AUC}_{0-2 \mathrm{~h}}$ of plasma aGLP1 from baseline by about two times, while no significant change was noted for 3 days observation in a control group without canagliflozin $(\mathrm{n}=15)$. Notably, the increase in plasma aGLP-1 with canagliflozin reached a maximum at $30 \mathrm{~min}$ and was maintained from 0 to $2 \mathrm{~h}$. Addition of teneligliptin resulted in a further increase of plasma aGLP-1, with an approximately fourfold increase of $\mathrm{AUC}_{0-2 \mathrm{~h}}$ compared with that at baseline. In contrast, canagliflozin had no influence on the active GIP level in plasma.

\section{Sotagliflozin}

Sotagliflozin is a dual SGLT1/SGLT2 inhibitor that is currently under development in a phase 3 study for type 1 diabetes. A similar phase 3 study for type 2 diabetes is expected to start by the end of 2016.

\section{Pharmacokinetics and pharmacodynamics}

In healthy subjects, the maximum circulating concentration of sotagliflozin was $165 \mathrm{ng} / \mathrm{mL}$ at day 7 after multiple-dose administration, and $t_{1 / 2}$ was $29 \mathrm{~h}$ [23]. Approximately $70 \%$ of sotagliflozin is rapidly absorbed and reaches the circulation within $15 \mathrm{~min}$. In patients with type 2 diabetes, a maximum 
plasma concentration of $230-307 \mathrm{ng} / \mathrm{mL}$ was reached at 30 min to $2 \mathrm{~h}$ after administration of $300 \mathrm{mg}$ of sotagliflozin, with $\mathrm{a} \mathrm{t}_{1 / 2}$ of $13.5 \pm 5.3 \mathrm{~h}$ and a steady-state plasma concentration achieved between days 7 and 14 [31]. Sotagliflozin is mostly eliminated in a glucoside form in the urine, and is partially eliminated unchanged in the feces in healthy subjects [20]. Similarly to canagliflozin, the blood level of sotagliflozin is insufficient to inhibit systemic SGLT1, while the level in the lumen in the gastrointestinal tract is high enough to inhibit SGLT1 [31]. The IC50 values of sotagliflozin are $36 \mathrm{nM}$ for human SGLT1 and $1.8 \mathrm{nM}$ for human SGLT2, with selectivity of 20-fold for SGLT2 over SGLT1 [31]. Sotagliflozin has approximately similar potency for inhibition of SGLT2 compared with other SGLT2 inhibitors, such as dapagliflozin, empagliflozin and canagliflozin, but is about 10 -fold more potent than canagliflozin for inhibition of SGLT1 [21, 31]. The maximum UGE was $44 \mathrm{~g}$ at $24 \mathrm{~h}$ after a single dose of sotagliflozin at $300 \mathrm{mg}$, and the maximum UGE on day 7 after multiple dosing was $36 \mathrm{~g}[23,30]$, reflecting the SGLT2 inhibitory effect of sotagliflozin in the kidney. This UGE is somewhat lower than those reported for other SGLT2 inhibitors: dapagliflozin (62 g) [47], canagliflozin (70 g) [48] and empagliflozin (74 g) [49]. The relative weak effect of sotagliflozin for UGE may be due to the improved glycemic control through mechanisms based on SGLT1 inhibition.

\section{Clinical efficacy of sotagliflozin for glycemic control}

In a phase 2 a clinical trial in type 2 diabetes not adequately controlled with metformin $(n=36)$, patients were divided into three groups: sotagliflozin $150 \mathrm{mg}$ a day $(\mathrm{n}=12), 300 \mathrm{mg}$ a day $(\mathrm{n}=12)$, and placebo $(\mathrm{n}=12)$ [31]. Sotagliflozin treatment for 28 days decreased $\mathrm{HbA} 1 \mathrm{c}$ by $-1.15 \%$ at $150 \mathrm{mg}$ and $-1.25 \%$ at $300 \mathrm{mg}$ from baseline (8.2\% and $8.5 \%$, respectively) vs. $-0.49 \%$ with placebo $(8.2 \%)$. In a phase $2 \mathrm{~b}$ dose-ranging study of sotagliflozin in patients with type 2 diabetes poorly controlled with metformin $(n=299)$, groups with HbAlc at baseline of $8.0 \%, 8.3 \%, 8.4 \%, 8.1 \%$ and $7.9 \%$ were treated with $75 \mathrm{mg}$ once daily $(\mathrm{n}=59), 200 \mathrm{mg}$ once daily $(\mathrm{n}=60)$, $200 \mathrm{mg}$ twice daily $(\mathrm{n}=60), 400 \mathrm{mg}$ once daily $(\mathrm{n}=60)$, and placebo $(n=60)$, respectively [50]. Sotagliflozin significantly and dose-dependently decreased $\mathrm{HbA} 1 \mathrm{c}$ from baseline by $0.42 \%, 0.52 \%, 0.80 \%$, and $0.92 \%$ in 12 weeks treatment at these respective doses, while reduction of $\mathrm{HbAlc}$ with placebo was only $0.09 \%$. The reduction of $\mathrm{HbA} 1 \mathrm{c}$ at $400 \mathrm{mg}$ once daily was similar to that achieved with the maximum dose of canagliflozin (300 mg once daily).

\section{Effect of sotagliflozin on circulating GLP-1: animal studies}

Sotagliflozin significantly increased circulating aGLP-1, tGLP-1 and PYY in mice from 30 min to $6 \mathrm{~h}$ after meal challenge [27]. The increases in GLP-1 and PYY were significantly associated with increases in total glucose in the small intestine, cecum and colon, compared with a vehicle group. The increases in glucose were maintained over $6 \mathrm{~h}$, suggesting that inhibition of SGLT1 in the gastrointestinal tract by sotag- liflozin is sustained for a relatively long time. In addition, the increase of glucose in the gastrointestinal tract was associated with a decrease in $\mathrm{pH}$ in the cecum. Significant increases in circulating levels of aGLP-1, tGLP-1 and PYY, and of glucose in the small intestine, cecum and colon after a glucose-containing meal challenge also occurred in SGLT1-/- mice that were littermates of the SGLT1+/+ mice. The peak aGLP-1 level in SGLT1-/- mice occurred at $1 \mathrm{~h}$ after the meal test, corresponding to the peak in the glucose level in the small intestine [27]. Similarly, in obese male C57BL6J mice fed a high fat diet, single dose sotagliflozin or sitagliptin was associated with a significant increase in $\mathrm{AUC}_{0-6 \mathrm{~h}}$ for aGLP-1 after meal challenge, and combination therapy with these drugs markedly elevated the AUC for aGLP-1. After 14 days of once-a-day administration, sotagliflozin and sitagliptin monotherapy also increased plasma aGLP-1 between 0 and $6 \mathrm{~h}$ after meal challenge compared with the vehicle, and combination therapy further increased aGLP-1 [28]. In KKAy mice (a model of type 2 diabetes), a significant increase of tGLP-1 at $2 \mathrm{~h}$ after glucose challenge was found with sotagliflozin compared with vehicle [29]. Interestingly, in this study, long-term sotagliflozin treatment caused an increase in food consumption in KKAy mice, as well as in lean rats and dogs, but not in OP-CD rats (an obese rat model) [29].

\section{Effect of sotagliflozin on circulating GLP-1: clinical studies}

In healthy subjects $(n=12$; treatment 10 , placebo 2$)$, sotagliflozin significantly increased aGLP-1, tGLP-1 and PYY and significantly reduced postprandial glucose relative to placebo after breakfast [30]. In a single-dose study of sotagliflozin at $300 \mathrm{mg}$ in 12 patients with type 2 diabetes, there was a significant increase in UGE throughout the day after dosing, significant increases in aGLP-1, tGLP-1, and PYY, and significant decreases in plasma glucose and insulin between 0 and $13 \mathrm{~h}$ [31]. In a single center, three-treatment, three-crossover, randomized, open-label study in patients with type 2 diabetes $(\mathrm{n}=$ 18), sotagliflozin monotherapy and combination therapy with sitagliptin increased 24-h UGE to similar degrees, suggesting that sitagliptin did not affect UGE. Sotagliflozin given once a day before a morning meal did not significantly increase aGLP-1 from baseline. Combination therapy of sotagliflozin and sitagliptin once a day before a morning meal increased aGLP-1, tGLP-1 and PYY, and decreased total GIP, compared with sitagliptin monotherapy. The concentrations of aGLP-1 at $2 \mathrm{~h}$ after a morning meal and $2 \mathrm{~h}$ after lunch were approximate 10 and 15-20 pM, respectively, with combination therapy, compared to approximate 5 and $7 \mathrm{pM}$, respectively, at baseline (control) [28].

\section{Mechanisms of Elevation of Circulating GLP-1 by SGLT2 Inhibitors}

The amount of secreted GLP-1 is associated with the size of a meal and the rate of gastric emptying after the meal [51, 52]. Fasting plasma GLP-1 is usually maintained at a very low lev- 
el [53]. Generally, elevation of plasma GLP-1 has a biphasic pattern with the early phase in 15 - 30 min and a second small peak at 90 - 120 min after a meal [54]. Few L cells, which secrete GLP-1, are expressed in the upper intestine in rodents and humans, but these cells are abundantly expressed in the lower intestine [55]. Orally ingested food requires several hours to reach the lower intestine [56], and thus it is unlikely that GLP-1 elevation in the early phase is explained by a direct effect of food on L cells in the lower small intestine. This suggests that indirect mechanisms, such as endocrine or neural responses, may be involved [57], and it is known that neurons and microvessels are located near L cells $[58,59]$. Further, in rodents, GIP secreted from K cells on the brush-border in the upper small intestine by direct effects of food stimulates the afferent vagal nerve $[57,60,61]$. This stimulation results in activation of efferent cholinergic neurons, and acetylcholine secreted from nerve termini promotes GLP-1 secretion in L cells in the lower small intestine, either directly or via the gastrinreleasing peptide (GRP)-secreted nerve [58, 61-63]. However, GIP stimulation of the afferent vagal nerve has not been shown in humans [64].

Recent evidence suggests that the few L cells in the upper intestine may be responsible for the rapid phase of GLP-1 elevation $[53,65]$. Therefore, in a normal physiological state in humans, a direct effect of nutrients on L cells may play the main role in rapid elevation of GLP-1. However, stimulation of SGLT3, a glucose sensor expressed mainly in the upper small intestine that does not transport glucose, has recently been shown to promote GLP-1 secretion (probably promptly) and glucose absorption in the more distal intestine via an effect on the afferent vagal nerve in a rats-model [66]. Therefore, probably this mechanism may also partly explain the early phase elevation of GLP-1 after meals, although the mechanisms independent of SGLT3, but via vagal nerve, may be possible. The precise location of the cells that express SGLT3 in the upper intestine is still uncertain $[67,68]$. Importantly, GLP-1 secretion by glucose stimulation in L cells mainly occurs via SGLT1 [69]. However, physiologically in humans, most orally digested carbohydrate or glucose is absorbed in the upper intestine and most does not reach the lower intestine [61]. Therefore, it is unlikely that GLP-1 secretion by glucose stimulation via SGLT1 in the lower small intestine fully explains the late (second) peak of GLP-1 secretion after meals. On the other hand, fatty acids from meals can reach the lower intestine, and it may be more plausible that the second peak of GLP-1 is due to a mechanism based on direct stimulation of $G$ protein coupled receptor (GPR) 40 (also known as free fatty acid receptor (FFAR)1), GPR119, and GPR120 (FFAR4) by fatty acids [70-74].

Canagliflozin (mildly) and sotagliflozin (moderately) inhibit SGLT1 in the upper intestine, which suggests that these drugs should prevent (rather than promote) early phase elevation of GLP-1. However, canagliflozin does not inhibit early phase GLP-1 elevation after a meal in healthy subjects [26], and significantly promoted this effect in our study in patients with type 2 diabetes, as described above [46]. This finding is basically consistent with the postprandial elevation of GLP1 in SGLT1-/- mice [27]. Similar findings were obtained for sotagliflozin in healthy subjects [30] and in patients with type
2 diabetes [31]. Speculatively, these results may be partly explained by enhanced SGLT3 stimulation by increased glucose in the intestine lumen due to inhibition of SGLT1 in the upper intestine, resulting in acute promotion of GLP- 1 secretion by probable L cells in the lower intestine via an effect mediated by the afferent vagal nerve; however, there is no evidence to support this hypothesis in animal models or clinical studies. Other mechanisms occurring via the afferent vagal nerve and associated with SGLT1 inhibition in the upper intestine, but independent of SGLT3 stimulation, may also be present. A mechanism independent of SGLT1 inhibition may also occur, because empagliflozin, a highly selective SGLT2 inhibitor with selectivity of 2,680-fold over SGLT1 [21], also promotes GLP-1 secretion after a meal in patients with type 2 diabetes [32]. A single dose of empagliflozin ( $25 \mathrm{mg}$ ) following chronic administration for 4 weeks increased plasma aGLP-1 after mix meal dosing, although the elevation appeared to be relatively mild, especially when empagliflozin was given chronically. Interestingly, empagliflozin increased plasma GLP-1 levels, as well as endogenous glucose production (EGP) and glucagon, even before a meal. These changes may be associated with increased UGE by SGLT2 inhibition, but the mechanisms are unknown. Taken together, these findings suggest that SGLT2 inhibition itself might contribute to plasma GLP-1 elevation, probably via indirect mechanisms, although the effect via this mechanism appears to be mild.

The effects of canagliflozin and sotagliflozin on the second peak (late phase) of GLP-1 elevation after a meal may occur through different mechanisms for the two drugs. Due to SGLT1 inhibition by these drugs, most glucose derived from food reaches the lower intestine without absorption in the upper intestine [75]. SGLT1 inhibition of canagliflozin in the intestinal lumen is transient and vanishes in a few hours [25]. Therefore, the effect of canagliflozin has almost disappeared when glucose reaches the lower intestine, and the increased glucose level can directly stimulate GLP-1 secretion via SGLT1 in L cells in the lower small intestine. In contrast, sotagliflozin is a long-acting SGLT1 inhibitor in the intestinal lumen, and the effect may be maintained for 1 day $[27,28]$. Sotagliflozin is partially eliminated unchanged in the feces [20], and thus it is unlikely that sotagliflozin promotes GLP-1 secretion by glucose stimulation of SGLT1 in L cells. The most plausible explanation for late phase GLP-1 elevation after a meal by sotagliflozin may be based on mechanisms mediated by short chain fatty acids (SCFAs) such as acetate, butyrate, and propionate $[27,74]$. SCFAs produced by bacterial fermentation of glucose which reached the colon due to SGLT1 inhibition by sotagliflozin in the upper small intestine probably can directly simulate GLP-1 secretion via GPR41 (FFAR3) and GPR43 (FFAR2) in L cells in the colon $[28,75]$. The effect of GLP-1 elevation in the late phase by canagliflozin also may be partially based on this mechanism, but it is unclear which of the effect via SGLT1 by glucose stimulation or that via GPR41/43 by SCFA stimulation is predominant for this agent. Furthermore, GLP-1 elevation in the late phase, as well as in the early phase, may occur independently of increased glucose in the lower intestine or colon, probably via mechanisms indirectly associated with increased UGE by SGLT2 inhibition, because empagliflozin mildly increases plasma GLP-1 in both phases [32]. 
Taken together, the detailed mechanisms of plasma GLP-1 elevation in the early phase by canagliflozin or sotagliflozin remain largely unclear. However, a mechanism via afferent vagal nerve activation mediated by increased SGLT3 stimulation due to an increase of glucose in the upper intestine based on SGLT1 inhibition or other mechanisms, independently of SGLT3, might be involved. In addition, mechanisms independent of SGLT1 inhibition and indirect via SGLT2 inhibition may be involved. Late phase elevation of plasma GLP-1 may involve glucose stimulation of SGLT1 (canagliflozin) and SCFA stimulation of GPR41/43 (sotagliflozin and possibly canagliflozin) in L cells. Mechanisms independent of SGLT1 inhibition and associated with SGLT2 inhibition may also be involved.

\section{Conclusion and Future Perspectives}

The UKPDS study showed that earlier strict intervention for glycemic control can prevent progression of microvascular complications in patients with type 2 diabetes [76]. Additionally, longer observation over 10 years after the intervention in the UKPDS study showed that this earlier intervention for glycemic control after onset of type 2 diabetes suppressed cardiovascular events [77]. This suggests the importance of strict glycemic control in the early stage for inhibition of progression of both micro- and macrovascular complications.

On the other hand, a hypoglycemia attack caused by treatment for diabetes [78] or obesity [79] can be a risk factor for cardiovascular events. In this respect, SGLT2 inhibitors may have an advantage for treatment of type 2 diabetes from an earlier stage because of their effect on decreasing body weight, a low risk for hypoglycemia, and a glucose-lowering effect independent of insulin action $[1,2]$. However, combination therapy may also be important to achieve stricter glycemic control if the effect of monotherapy is insufficient. Thus, addition of a DPP4 inhibitor to an SGLT2 inhibitor may be reasonable because DPP4 inhibitors generally do not increase body weight or hypoglycemia when used without sulfonylureas or insulin [80].

Combination therapy with SGLT2 inhibitors with low SGLT2/SGLT1 selectivity such as canagliflozin or sotagliflozin and a DPP4 inhibitor markedly enhances elevation of circulating active GLP-1 compared with DPP4 inhibitor monotherapy $[24,25,28]$. Notably, recent clinical trials have shown that DPP4 inhibitors do not reduce cardiovascular events and mortality $[4,5,6]$, whereas these events were significantly suppressed by liraglutide, a GLP-1 receptor agonist [81]. It is unclear whether a difference in the degree of elevation of plasma active GLP-1 or liraglutide between treatments by DPP4 inhibitors and by liraglutide can explain these results. However, this finding also suggests that a combination of a canagliflozin or sotagliflozin and a DPP4 inhibitor might provide beneficial effects associated with enhanced elevation of circulating active GLP-1 levels.

Several issues remain to be clarified. First, it is unclear if significant elevation of circulating GLP-1 is specific for SGLT2 inhibitors with low SGLT2/SGLT1 selectivity such as canagliflozin and sotagliflozin, which has a potent SGLT1 inhibitory effect. The clinical significance of involvement of intestinal SGLT1 inhibition on elevation of circulating GLP-1 by SGLT2 inhibitors remains unclear and the mechanisms are probably complex. Second, it will be interesting to investigate whether there is a difference in elevation of circulating GLP-1 between SGLT2 inhibitors with a long acting and relatively strong intestinal SGLT1 inhibitory effect, such as sotagliflozin, and those with a short acting and mild intestinal SGLT1 inhibitory effect, such as canagliflozin. Finally, there is a need to clarify whether the extent of elevation of active GLP-1 by combination therapy with a DPP4 inhibitor and a canagliflozin or sotagliflozin is sufficient to provide a clinically significant effect on glycemic control and a potential protective effect of GLP-1 on cardiovascular events.

In conclusion, SGLT2 inhibitors with low SGLT2/SGLT1 selectivity such as canagliflozin and sotagliflozin can significantly elevate circulating active GLP-1 levels, especially when used in combination with DPP4 inhibitors. This combination therapy may serve as a new strategy for treatment of patients with type 2 diabetes in this aspect.

\section{Conflicts of Interest}

Authors have no interest to disclose.

\section{Grant Support}

None.

\section{Author Contributions}

KT wrote this manuscript. TI reviewed the manuscript.

\section{References}

1. Wilding JP. The role of the kidneys in glucose homeostasis in type 2 diabetes: clinical implications and therapeutic significance through sodium glucose co-transporter 2 inhibitors. Metabolism. 2014;63(10):1228-1237.

2. Ferrannini E, Solini A. SGLT2 inhibition in diabetes mellitus: rationale and clinical prospects. Nat Rev Endocrinol. 2012;8(8):495-502.

3. Zinman B, Wanner C, Lachin JM, Fitchett D, Bluhmki E, Hantel S, Mattheus M, et al. Empagliflozin, Cardiovascular Outcomes, and Mortality in Type 2 Diabetes. N Engl J Med. 2015;373(22):2117-2128.

4. Scirica BM, Bhatt DL, Braunwald E, Steg PG, Davidson J, Hirshberg B, Ohman P, et al. Saxagliptin and cardiovascular outcomes in patients with type 2 diabetes mellitus. N Engl J Med. 2013;369(14):1317-1326.

5. White WB, Cannon CP, Heller SR, Nissen SE, Bergenstal RM, Bakris GL, Perez AT, et al. Alogliptin after acute coronary syndrome in patients with type 2 diabetes. $\mathrm{N}$ 
Engl J Med. 2013;369(14):1327-1335.

6. Green JB, Bethel MA, Armstrong PW, Buse JB, Engel SS, Garg J, Josse R, et al. Effect of Sitagliptin on Cardiovascular Outcomes in Type 2 Diabetes. N Engl J Med. 2015;373(3):232-242.

7. Chia CW, Egan JM. Incretin-based therapies in type 2 diabetes mellitus. J Clin Endocrinol Metab. 2008;93(10):3703-3716.

8. Fujita Y, Inagaki N. Renal sodium glucose cotransporter 2 inhibitors as a novel therapeutic approach to treatment of type 2 diabetes: Clinical data and mechanism of action. J Diabetes Investig. 2014;5(3):265-275.

9. Kanai Y, Lee WS, You G, Brown D, Hediger MA. The human kidney low affinity $\mathrm{Na}+$ /glucose cotransporter SGLT2. Delineation of the major renal reabsorptive mechanism for D-glucose. J Clin Invest. 1994;93(1):397404.

10. Abdul-Ghani MA, Norton L, Defronzo RA. Role of sodium-glucose cotransporter 2 (SGLT 2) inhibitors in the treatment of type 2 diabetes. Endocr Rev. 2011;32(4):515531.

11. Rahmoune H, Thompson PW, Ward JM, Smith CD, Hong $\mathrm{G}$, Brown J. Glucose transporters in human renal proximal tubular cells isolated from the urine of patients with noninsulin-dependent diabetes. Diabetes. 2005;54(12):34273434.

12. Seufert J. SGLT2 inhibitors - an insulin-independent therapeutic approach for treatment of type 2 diabetes: focus on canagliflozin. Diabetes Metab Syndr Obes. 2015;8:543-554.

13. Gorboulev V, Schurmann A, Vallon V, Kipp H, Jaschke A, Klessen D, Friedrich A, et al. Na(+)-D-glucose cotransporter SGLT1 is pivotal for intestinal glucose absorption and glucose-dependent incretin secretion. Diabetes. 2012;61(1):187-196.

14. Harada N, Inagaki N. Role of sodium-glucose transporters in glucose uptake of the intestine and kidney. J Diabetes Investig. 2012;3(4):352-353.

15. Abdul-Ghani MA, DeFronzo RA, Norton L. Novel hypothesis to explain why SGLT2 inhibitors inhibit only $30-50 \%$ of filtered glucose load in humans. Diabetes. 2013;62(10):3324-3328.

16. Drozdowski LA, Thomson AB. Intestinal sugar transport. World J Gastroenterol. 2006;12(11):1657-1670.

17. Kanai Y, Stelzner M, Nussberger S, Khawaja S, Hebert SC, Smith CP, Hediger MA. The neuronal and epithelial human high affinity glutamate transporter. Insights into structure and mechanism of transport. J Biol Chem. 1994;269(32):20599-20606.

18. Dyer J, Wood IS, Palejwala A, Ellis A, Shirazi-Beechey SP. Expression of monosaccharide transporters in intestine of diabetic humans. Am J Physiol Gastrointest Liver Physiol. 2002;282(2):G241-248.

19. Lindquist B, Meeuwisse GW. Chronic diarrhoea caused by monosaccharide malabsorption. Acta Paediatr. 1962;51:674-685.

20. Cariou B, Charbonnel B. Sotagliflozin as a potential treatment for type 2 diabetes mellitus. Expert Opin Investig Drugs. 2015;24(12):1647-1656.
21. Kurosaki E, Ogasawara H. Ipragliflozin and other sodium-glucose cotransporter-2 (SGLT2) inhibitors in the treatment of type 2 diabetes: preclinical and clinical data. Pharmacol Ther. 2013;139(1):51-59.

22. Liang Y, Arakawa K, Ueta K, Matsushita Y, Kuriyama C, Martin T, Du F, et al. Effect of canagliflozin on renal threshold for glucose, glycemia, and body weight in normal and diabetic animal models. PLoS One. 2012;7(2):e30555.

23. Lapuerta P, Zambrowicz B, Strumph P, Sands A. Development of sotagliflozin, a dual sodium-dependent glucose transporter 1/2 inhibitor. Diab Vasc Dis Res. 2015;12(2):101-110.

24. Oguma T, Kuriyama C, Nakayama K, Matsushita Y, Yoshida K, Kiuchi S, Ikenaga Y, et al. The effect of combined treatment with canagliflozin and teneligliptin on glucose intolerance in Zucker diabetic fatty rats. J Pharmacol Sci. 2015;127(4):456-461.

25. Oguma T, Nakayama K, Kuriyama C, Matsushita Y, Yoshida K, Hikida K, Obokata N, et al. Intestinal Sodium Glucose Cotransporter 1 Inhibition Enhances GlucagonLike Peptide-1 Secretion in Normal and Diabetic Rodents. J Pharmacol Exp Ther. 2015;354(3):279-289.

26. Polidori D, Sha S, Mudaliar S, Ciaraldi TP, Ghosh A, Vaccaro N, Farrell K, et al. Canagliflozin lowers postprandial glucose and insulin by delaying intestinal glucose absorption in addition to increasing urinary glucose excretion: results of a randomized, placebo-controlled study. Diabetes Care. 2013;36(8):2154-2161.

27. Powell DR, Smith M, Greer J, Harris A, Zhao S, DaCosta C, Mseeh F, et al. LX4211 increases serum glucagon-like peptide 1 and peptide YY levels by reducing sodium/glucose cotransporter 1 (SGLT1)-mediated absorption of intestinal glucose. J Pharmacol Exp Ther. 2013;345(2):250259.

28. Zambrowicz B, Ding ZM, Ogbaa I, Frazier K, Banks P, Turnage A, Freiman J, et al. Effects of LX4211, a dual SGLT1/SGLT2 inhibitor, plus sitagliptin on postprandial active GLP-1 and glycemic control in type 2 diabetes. Clin Ther. 2013;35(3):273-285.e7.

29. Powell DR, DaCosta CM, Smith M, Doree D, Harris A, Buhring L, Heydorn W, et al. Effect of LX4211 on glucose homeostasis and body composition in preclinical models. J Pharmacol Exp Ther. 2014;350(2):232-242.

30. Zambrowicz B, Ogbaa I, Frazier K, Banks P, Turnage A, Freiman J, Boehm KA, et al. Effects of LX4211, a dual sodium-dependent glucose cotransporters 1 and 2 inhibitor, on postprandial glucose, insulin, glucagon-like peptide 1 , and peptide tyrosine tyrosine in a dose-timing study in healthy subjects. Clin Ther. 2013;35(8):11621173.e8.

31. Zambrowicz B, Freiman J, Brown PM, Frazier KS, Turnage A, Bronner J, Ruff D, et al. LX4211, a dual SGLT1/ SGLT2 inhibitor, improved glycemic control in patients with type 2 diabetes in a randomized, placebo-controlled trial. Clin Pharmacol Ther. 2012;92(2):158-169.

32. Ferrannini E, Muscelli E, Frascerra S, Baldi S, Mari A, Heise T, Broedl UC, et al. Metabolic response to sodiumglucose cotransporter 2 inhibition in type 2 diabetic pa- 
tients. J Clin Invest. 2014;124(2):499-508.

33. Janssen Pharmaceuticals Inc. InvokanaTM (canagliflozin) tablets, for oral use: US prescribing information. Available from: http://www.janssenmd.com/pdf/invokana/PI-INVOKANA.pdf.

34. INVOKANA ${ }^{\mathrm{TM}}$ (canagliflozin) tablets, for oral use [package insert] Janssen Pharmaceuticals, Titusville, NJ. 2013.

35. INVOKANA ${ }^{\mathrm{TM}}$ (canagliflozin) tablets, for oral use [Summary of Product Characteristics] Janssen-Cilag International NV, Beerse, Belgium. 2013.

36. Janssen Pharmaceuticals Inc. Endocrinologic and metabolic drugs advisory committee: canagliflozin as an adjunctive treatment to diet and exercise alone or co-administered with other antihyperglycemic agents to improve glycemic control in adults with type 2 diabetes mellitus. Available from: http://www.fda.gov/downloads/AdvisoryCommittees/.../UCM334551.pdf.

37. European Medicins Agency [http://ema.europa.eu/ema/]. 2014.

38. Kuriyama C, Xu JZ, Lee SP, Qi J, Kimata H, Kakimoto T, Nakayama K, et al. Analysis of the effect of canagliflozin on renal glucose reabsorption and progression of hyperglycemia in zucker diabetic Fatty rats. J Pharmacol Exp Ther. 2014;351(2):423-431.

39. Sha S, Polidori D, Farrell K, Ghosh A, Natarajan J, Vaccaro N, Pinheiro J, et al. Pharmacodynamic differences between canagliflozin and dapagliflozin: results of a randomized, double-blind, crossover study. Diabetes Obes Metab. 2015;17(2):188-197.

40. Stenlof K, Cefalu WT, Kim KA, Alba M, Usiskin K, Tong $\mathrm{C}$, Canovatchel W, et al. Efficacy and safety of canagliflozin monotherapy in subjects with type 2 diabetes mellitus inadequately controlled with diet and exercise. Diabetes Obes Metab. 2013;15(4):372-382.

41. Cefalu WT, Leiter LA, Yoon KH, Arias P, Niskanen L, Xie J, Balis DA, et al. Efficacy and safety of canagliflozin versus glimepiride in patients with type 2 diabetes inadequately controlled with metformin (CANTATA-SU): 52 week results from a randomised, double-blind, phase 3 non-inferiority trial. Lancet. 2013;382(9896):941-950.

42. Lavalle-Gonzalez FJ, Januszewicz A, Davidson J, Tong C, Qiu R, Canovatchel W, Meininger G. Efficacy and safety of canagliflozin compared with placebo and sitagliptin in patients with type 2 diabetes on background metformin monotherapy: a randomised trial. Diabetologia. 2013;56(12):2582-2592.

43. Zaccardi F, Webb DR, Htike ZZ, Youssef D, Khunti $\mathrm{K}$, Davies MJ. Efficacy and safety of sodium-glucose cotransporter 2 inhibitors in type 2 diabetes mellitus: Systematic review and network meta-analysis. Diabetes Obes Metab. 2016;18(8):783-794.

44. Koda S, Date Y, Murakami N, Shimbara T, Hanada T, Toshinai K, Niijima A, et al. The role of the vagal nerve in peripheral PYY3-36-induced feeding reduction in rats. Endocrinology. 2005;146(5):2369-2375.

45. De Silva A, Bloom SR. Gut Hormones and Appetite Control: A focus on PYY and GLP-1 as therapeutic targets in obesity. Gut Liver. 2012;6(1):10-20.

46. Takebayashi K, Hara K, Terasawa T, Naruse R, Suetsugu
M, Tsuchiya T, Inukai T. Effect of canagliflozin on circulating active GLP-1 levels in patients with type 2 diabetes: a randomized trial. Endocr J. 2017. (in press).

47. Komoroski B, Vachharajani N, Feng Y, Li L, Kornhauser D, Pfister M. Dapagliflozin, a novel, selective SGLT2 inhibitor, improved glycemic control over 2 weeks in patients with type 2 diabetes mellitus. Clin Pharmacol Ther. 2009;85(5):513-519.

48. Sha S, Devineni D, Ghosh A, Polidori D, Chien S, Wexler D, Shalayda K, et al. Canagliflozin, a novel inhibitor of sodium glucose co-transporter 2, dose dependently reduces calculated renal threshold for glucose excretion and increases urinary glucose excretion in healthy subjects. Diabetes Obes Metab. 2011;13(7):669-672.

49. Sarashina A, Koiwai K, Seman LJ, Yamamura N, Taniguchi A, Negishi T, Sesoko S, et al. Safety, tolerability, pharmacokinetics and pharmacodynamics of single doses of empagliflozin, a sodium glucose cotransporter 2 (SGLT2) inhibitor, in healthy Japanese subjects. Drug Metab Pharmacokinet. 2013;28(3):213-219.

50. Rosenstock J, Cefalu WT, Lapuerta P, Zambrowicz B, Ogbaa I, Banks P, Sands A. Greater dose-ranging effects on A1C levels than on glucosuria with LX4211, a dual inhibitor of SGLT1 and SGLT2, in patients with type 2 diabetes on metformin monotherapy. Diabetes Care. 2015;38(3):431-438.

51. Vilsboll T, Krarup T, Sonne J, Madsbad S, Volund A, Juul AG, Holst JJ. Incretin secretion in relation to meal size and body weight in healthy subjects and people with type 1 and type 2 diabetes mellitus. J Clin Endocrinol Metab. 2003;88(6):2706-2713.

52. Miholic J, Orskov C, Holst JJ, Kotzerke J, Meyer HJ. Emptying of the gastric substitute, glucagon-like peptide-1 (GLP-1), and reactive hypoglycemia after total gastrectomy. Dig Dis Sci. 1991;36(10):1361-1370.

53. Holst JJ. The physiology of glucagon-like peptide 1 . Physiol Rev. 2007;87(4):1409-1439.

54. Rask E, Olsson T, Soderberg S, Johnson O, Seckl J, Holst JJ, Ahren B, et al. Impaired incretin response after a mixed meal is associated with insulin resistance in nondiabetic men. Diabetes Care. 2001;24(9):1640-1645.

55. Eissele R, Goke R, Willemer S, Harthus HP, Vermeer H, Arnold R, Goke B. Glucagon-like peptide-1 cells in the gastrointestinal tract and pancreas of rat, pig and man. Eur J Clin Invest. 1992;22(4):283-291.

56. Camilleri M, Colemont LJ, Phillips SF, Brown ML, Thomforde GM, Chapman N, Zinsmeister AR. Human gastric emptying and colonic filling of solids characterized by a new method. Am J Physiol. 1989;257(2 Pt 1):G284-290.

57. Roberge JN, Brubaker PL. Regulation of intestinal proglucagon-derived peptide secretion by glucose-dependent insulinotropic peptide in a novel enteroendocrine loop. Endocrinology. 1993;133(1):233-240.

58. Anini Y, Hansotia T, Brubaker PL. Muscarinic receptors control postprandial release of glucagon-like peptide-1: in vivo and in vitro studies in rats. Endocrinology. 2002;143(6):2420-2426.

59. Hansen L, Deacon CF, Orskov C, Holst JJ. Glucagon-like 
peptide-1-(7-36)amide is transformed to glucagon-like peptide-1-(9-36)amide by dipeptidyl peptidase IV in the capillaries supplying the L cells of the porcine intestine. Endocrinology. 1999;140(11):5356-5363.

60. Rocca AS, Brubaker PL. Role of the vagus nerve in mediating proximal nutrient-induced glucagon-like peptide-1 secretion. Endocrinology. 1999;140(4):1687-1694.

61. Lim GE, Brubaker PL. Glucagon-like peptide 1 secretion by the L-cell. The view from within. Diabetes. 2006;55(Supplement 2):S70-S77.

62. Brubaker PL. Regulation of intestinal proglucagon-derived peptide secretion by intestinal regulatory peptides. Endocrinology. 1991;128(6):3175-3182.

63. Anini Y, Brubaker PL. Muscarinic receptors control glucagon-like peptide 1 secretion by human endocrine $\mathrm{L}$ cells. Endocrinology. 2003;144(7):3244-3250.

64. Nauck MA, Bartels E, Orskov C, Ebert R, Creutzfeldt W. Additive insulinotropic effects of exogenous synthetic human gastric inhibitory polypeptide and glucagon-like peptide-1-(7-36) amide infused at near-physiological insulinotropic hormone and glucose concentrations. J Clin Endocrinol Metab. 1993;76(4):912-917.

65. Pais R, Gribble FM, Reimann F. Stimulation of incretin secreting cells. Ther Adv Endocrinol Metab. 2016;7(1):2442.

66. Pal A, Rhoads DB, Tavakkoli A. Foregut exclusion disrupts intestinal glucose sensing and alters portal nutrient and hormonal milieu. Diabetes. 2015;64(6):1941-1950.

67. Diez-Sampedro A, Hirayama BA, Osswald C, Gorboulev V, Baumgarten K, Volk C, Wright EM, et al. A glucose sensor hiding in a family of transporters. Proc Natl Acad Sci U S A. 2003;100(20):11753-11758.

68. Freeman SL, Bohan D, Darcel N, Raybould HE. Luminal glucose sensing in the rat intestine has characteristics of a sodium-glucose cotransporter. Am J Physiol Gastrointest Liver Physiol. 2006;291(3):G439-445.

69. Kuhre RE, Frost CR, Svendsen B, Holst JJ. Molecular mechanisms of glucose-stimulated GLP-1 secretion from perfused rat small intestine. Diabetes. 2015;64(2):370382.

70. Dube PE, Brubaker PL. Nutrient, neural and endocrine control of glucagon-like peptide secretion. Horm Metab Res. 2004;36(11-12):755-760.
71. Edfalk S, Steneberg P, Edlund H. Gpr40 is expressed in enteroendocrine cells and mediates free fatty acid stimulation of incretin secretion. Diabetes. 2008;57(9):22802287.

72. Lauffer LM, Iakoubov R, Brubaker PL. GPR119 is essential for oleoylethanolamide-induced glucagon-like peptide-1 secretion from the intestinal enteroendocrine L-cell. Diabetes. 2009;58(5):1058-1066.

73. Chu ZL, Carroll C, Alfonso J, Gutierrez V, He H, Lucman A, Pedraza M, et al. A role for intestinal endocrine cell-expressed g protein-coupled receptor 119 in glycemic control by enhancing glucagon-like Peptide-1 and glucose-dependent insulinotropic Peptide release. Endocrinology. 2008;149(5):2038-2047.

74. Hirasawa A, Tsumaya K, Awaji T, Katsuma S, Adachi T, Yamada M, Sugimoto Y, et al. Free fatty acids regulate gut incretin glucagon-like peptide-1 secretion through GPR120. Nat Med. 2005;11(1):90-94.

75. Lehmann A, Hornby PJ. Intestinal SGLT1 in metabolic health and disease. Am J Physiol Gastrointest Liver Physiol. 2016;310(11):G887-898.

76. UK Prospective Diabetes Study (UKPDS) Group. Intensive blood-glucose control with sulphonylureas or insulin compared with conventional treatment and risk of complications in patients with type 2 diabetes (UKPDS 33). Lancet. 1998;352(9131):837-853.

77. Holman RR, Paul SK, Bethel MA, Matthews DR, Neil HA. 10-year follow-up of intensive glucose control in type 2 diabetes. N Engl J Med. 2008;359(15):1577-1589.

78. Goto A, Arah OA, Goto M, Terauchi Y, Noda M. Severe hypoglycaemia and cardiovascular disease: systematic review and meta-analysis with bias analysis. BMJ. 2013;347:f4533.

79. Colditz GA, Willett WC, Rotnitzky A, Manson JE. Weight gain as a risk factor for clinical diabetes mellitus in women. Ann Intern Med. 1995;122(7):481-486.

80. Dicembrini I, Pala L, Rotella CM. From theory to clinical practice in the use of GLP-1 receptor agonists and DPP-4 inhibitors therapy. Exp Diabetes Res. 2011;2011:898913.

81. Marso SP, Daniels GH, Brown-Frandsen K, Kristensen P, Mann JF, Nauck MA, Nissen SE, et al. Liraglutide and cardiovascular outcomes in type 2 diabetes. N Engl J Med. 2016;375(4):311-322. 